International Journal of Industrial Engineering Research and Development (IJIERD)

Volume 6, Issue 2, July-Dec 2015, pp. 29-33, Article ID: IJIERD_06_02_005

Available online at https://iaeme.com/Home/issue/IJIERD?Volume=6\&Issue $=2$

ISSN Print: 0976 - 6979 and ISSN Online: 0976 - 6987

DOI: https://doi.org/10.34218/IJIERD.6.2.2015.005

(C) IAEME Publication

\title{
INVENTORY MANAGEMENT: A SYSTEM CAPABLE OF REPORTING REAL TIME INVENTORY
}

\author{
Jatin S. Ajmera \\ Department of Mechanical Engineering, P.E.S Modern College of Engineering, \\ University of Pune, Maharashtra, India \\ Nikhil A. Sethi \\ Department of Mechanical Engineering, Pune Vidhyarthi Griha's College of \\ Engineering, University of Pune, Maharashtra, India \\ Shubham N. Karnawat \\ Department of Mechanical Engineering, P.E.S Modern College of Engineering, \\ University of Pune, Maharashtra, India
}

\begin{abstract}
The cost of a model not only depends on the type of features, but also depends on the easiness of the process and time taken to run it. The cost and features of the current model of GPS tracker are analyzed; the authors propose a new cost effective model and with significant features. The optimum solution is installing a Mobile Handset Module in the vehicle being transported. An active mobile phone module can be easily tracked by a service called "General Packet Radio Service (GPRS)". This new model caters to the need of the company and people and also offers a reduced price of reporting real time inventory.
\end{abstract}

Key words: Inventory Management, Mobile Handset Module, SAP system, SIM900 module

Cite this Article: Jatin S. Ajmera, Nikhil A. Sethi and Shubham N. Karnawat. Inventory Management: A System Capable of Reporting Real Time Inventory, International Journal of Industrial Engineering Research and Development, 6(2), 2015, pp. 29-33.

https://iaeme.com/Home/issue/IJIERD?Volume=6\&Issue=2

\section{INTRODUCTION}

The availability-demand of geopositioning devices has grown enormously is the last decade and is still increasing. A GPS tracking unit is a device, which uses Global positioning system to track the location of object moving or stationary. GPS has the capability of calculating position, time and velocity from any GPS receiver. Objective 
of this paper is to introduce a new idea of GPS tracking by companies or personnel which will be cost effective than the current models by using mobile handset module replacing the high cost current GPS tracking system. Mobile handset module includes GPRS Quadb and module for Arduino, SIM900 communication module which is lastly interfaced with the SAP/ERP system.

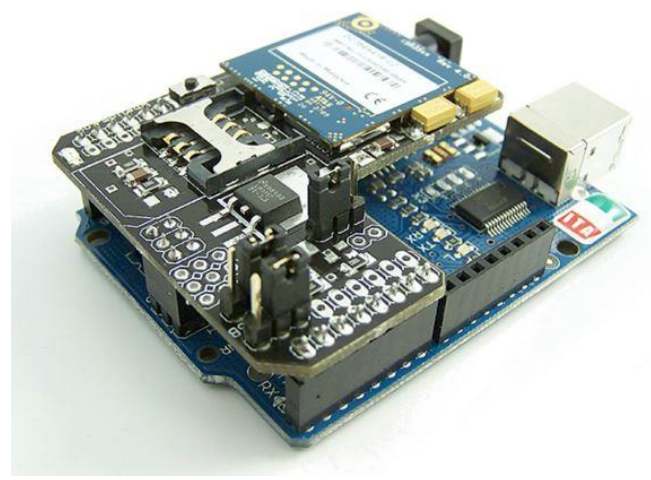

Figure 1 GPRS Quadband module with SIM900 using Arduino

The above said mobile handset module system will have the following features:

- Tracks of vehicles on the map: We can display the track currently being travelled by a vehicle, or any track taken by the vehicles in the past by selecting the dates which concern us.

- Detailed and proper trip descriptions: The device will monitor the location of the vehicle and will generate comprehensive statistics on the trip just a few minutes after it is completed. This includes the departure and arrival addresses, the distance travelled, the time spent travelling and stationary, and average speeds. The information then can be stored in servers

- Integration with other information systems: It can automatically transfer the entire information provided by the reports module to our own information system. The users $\log$ can $\log$ into SAP system to view all of the activities of the vehicles.

- Geofencing: The device will allow an area to be geofenced - marked on a map - and for a instruction to be added which triggers an alert in the events module whenever the vehicle leaves the marked area.

- Be the first to know: The module will notify you of any events that interest you via e-mail or SMS in a few seconds with an instant message.

\section{DISCUSSION}

Our business manages a great deal of inventory, which often signifies a high proportion of cost of goods sold. In order to stay organized and effective you need to know the location of inventory. Using the geo-fence feature, successive reports on this data can extract intelligence suggest patterns where process improvement might be a good idea to help reduce theft.

With mobile handset module, dealers can locate a vehicle in seconds. Some of the nation's largest used-car dealership groups use GPS technologies to lower repossession expenses and make the entire process simple and safe. But easy-to-use, palm-of-your-hand solutions make life easier for dealerships also capable of reporting real time inventory effectively.

All mobile companies practice the geo-fencing facility for applying the roaming charges on mobile devices; similarly this can be directly applied for Geo-Fencing by allotting specific areas and alert notification with the help of mobile companies. This 
system can be charged by placing a parallel electric circuit with the battery which will include voltage sensors to check the potential difference of the battery of mobile and the switch operated by this sensor to charge the battery when necessary. The proposed solution of using a mobile handset is appropriate to serve this purpose with GPRS feature pre-installed in the mobile phone. The module will be placed inside a tamper proof box which will be placed inside the bonnet of vehicle or under the steering or any suitable location. This system will be more reliable for tamper proofing if the company does not disclose this new installation to its customers and the dealer.

\section{INTERFACING MOBILE HANDSET MODULE WITH SAP/ ERP SYSTEM}

Our model is based on SAP applications, built around their latest R/3 system, which provides the capability to manage financial, asset, and cost accounting, production operations and materials, personnel, plants, and archived documents. The R/3 system runs on a number of platforms including Windows 2000 and uses the client/server model. The latest version of R/3 includes a comprehensive Internetenabled package.

SAP/ERP system will be integrated with our mobile handset module. The output of the module such as SMS will be the input given to the SAP/ERP system so that the following functions such as-

- vehicle tracking,

- model wise inventory at the dealers end \&

- sales made by the dealer

Can be integrated to the SAP/ERP system to get the exact inventory to the management.

The GSM module will be removed by the dealer prior to the delivery of the vehicle and the module will be sent back to the company for further usage.

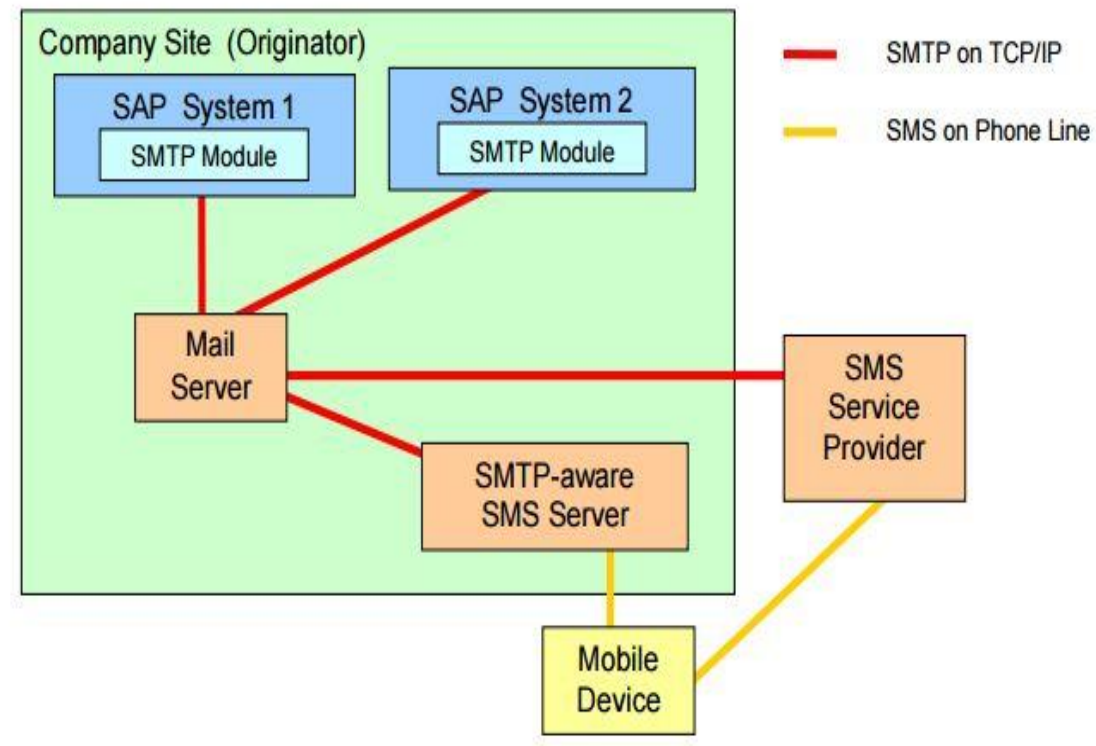

Figure 2 Interfacing SAP with mobile handset module 


\subsection{Prototype}

A model of the mobile handset module and software is developed to interface it with SAP/ERP system.

Geo-fencing and tracking: These operations will be interfaced with the SAP/ ERP system. The device will allow an area to be geofenced which will triggers an alert for any wrong path taken.

\section{Some Geo-fence-Break Possibilities}

- $\quad$ In case if vehicle moves out of the Geo-Fence area

Remedy: As soon as the vehicle moves out if the Geo-fenced area alert SMS will be sent to the company and the GPS position can be traced.

- In case of road blockage or diversions if the vehicle is supposed to move out of GeoFenced area and again it comes inside the Geo-fenced area

Remedy: As soon as the vehicle moves out or moves inside the Geo-fenced area alert SMS will be sent to the company and the GPS position can be traced.

\section{Tamper-Proofing}

The device will be fitted inside the vehicle and the power will be supplied from the battery of the vehicle using a voltage divider circuit to the device, in-order to ensure that the supply to the device is up-to the destination.

- $\quad$ Putting the device in an inaccessible (or hard to reach) location on the vehicle.

- $\quad$ Insuring the device casing is robust and difficult to access.

\section{Some Tampering Possibilities}

- A person can cut the supply of the device from vehicle battery.

Remedy: As soon as the wire is cut/ or the vehicle battery is stolen, the device will send alert SMS and GPS position of the vehicle. Even if the supply is cut, the device contains a self-battery which can run for few days and the information can be generated as per requirement.

- $\quad$ The device is stolen from the vehicle

Remedy: For stealing the device, as it has to be disconnected/ power cut from the vehicle battery, the alert SMS (as above) will be generated and sent to the company. In addition to this, as the device goes out of the set Geo-fenced area, again an alert SMS will be generated and the GPS position will be notified.

- $\quad$ Tampering with the device such as opening it.

Remedy: The sensors will detect any tampering made to the device and will send alert signal to the management.

\section{INVENTORY MANAGEMENT}

- As soon as the Tractor is produced and the quality dept. certifies that the same can be dispatched the GPS system will be installed in the said tractor. The unique number of GPS system, Engine number, chassis number, dealer name, invoice, transporter name, LR number will be updated in the ERP / SAP system and Real Time Inventory can be monitored. 
- The output of GPS system will be synchronized / integrated to ERP / SAP system through which Model wise inventory at Dealer's end and at Factory, daily sales, daily stock of vehicles in transit can be assessed.

- GPS System will help lower insurance rates. In some cases, banks offer better rates to dealers who use GPS System. More importantly, inventory management can help dealers improve customer experiences and close sales.

- Once the Tractor is sold the GPS System will be taken out by the dealer and send back to factory for re-usage.

\section{CONCLUSION}

Thus the model and concept proposed above relates to a GPS tracking system which is manufactured and installed at low cost i.e. Rs 2200/-, has appreciable features which caters to the profit for the companies wherein the inventory management is high.

Too much manual effort is spent on behind-the-scenes logistics. Affordable upcoming model can help companies maximize their bottom lines by eliminating inefficiencies, lowering operating costs and saving time. Mobile solution helps the company to cut down on communication costs i.e. information between the office and employees is exchanged digitally. This also leads to fewer phone calls and smaller bills. The staffs will no longer need to fill out journey logs on paper as all information is available in a centralized location. This technology enables dealers to control fuel costs as well as keep vehicles in the best possible condition. Sale-blocking embarrassments don't occur. This technology is particularly helpful to buy-here, payhere dealers. Thus, inventory management can help dealers improve customer experiences and close sales if the proposed concept is brought into practice.

\section{REFERENCES}

[1] K.Michael, A. McNamee, M. G. Michael, "The emerging ethics of humancentric GPS tacking and monitoring", International Conference on Mobile Business (2006), Research online, pp.1-15.

[2] S. Speck, J. Schaick, P. Bois, R. Haan, "Sensing Human Activity: GPS Tracking”, Sensors 2009, pp.3033-3055.

[3] A. Brown, J .Griesbach, B. Bockius, "GPS Tracking Location based service using wristwatch Geozigbee Sensors", ION publication (2007), pp.123-132.

[4] S. C. Speck, C. M. Langelaar, "Using GPS-Tracking Technology for Urban Design interventions", International Archives of the Photogrammetry, Remote Sensing \& Spatial Information Sciences, Vol XXXVIII-4/C21 pp.41-44

[5] A. K. Brown, M. A. Sturza, Navsys Corporation, "GPS Tracking System", Patent- US5379224A, 3-Jan-1995.

[6] James M. Gibson, Maptrek Llc, "Compact GPS tracker and customized mapping system", Patent-US6198431B1, 6-Mar-2001.

[7] D. R. Gildea, A. F. Lange, C. Abraham, Trimble Navigation Limited, "Compact GPS receiver/processor", US5861841A, 19-Jan-1999.

[8] Deepa H Kandpal and Khimya S Tinani. Inflationary Inventory Model Under Trade Credit Subject To Supply Uncertainty, International Journal of Management, 4(4), 2013, pp. 111 - 118.

[9] Dowlath Fathima and P.S Sheik Uduman. Single Period Inventory Model with Stochastic Demand and Partial Backlogging, International Journal of Management, 4(1), 2013, pp. 95 - 111. 